\title{
Application of Silane-treated Tea Waste Powder as a Potential Filler for Natural Rubber Composites
}

\author{
Nabil Hayeemasae, ${ }^{\mathrm{a}, *}$ and Hanafi Ismail ${ }^{\mathrm{b}}$ \\ The aim of this work was to develop sustainable composites based on \\ natural rubber (NR) and tea waste (TW) composites. The main concern \\ was the compatibility mismatch between NR and TW. The presence of \\ polar groups in the TW contributes to the weak interaction between \\ relatively hydrophobic NR and TW. Therefore, silane coupling agent was \\ introduced to enhance the properties of the composites. Treating the TW \\ by silane coupling agent greatly influenced the overall properties of the \\ composites. It speeded up the curing process due to its ability to reduce \\ possible adsorption of accelerator by TW. Better interaction between TW \\ and rubber matrix was clearly observed as evidenced by the maximum \\ torque $\left(M_{H}\right)$ and tensile properties of the composites. Such findings can be \\ verified by the $Q_{t} / Q_{g}$ values, indicating better rubber-filler interaction when \\ silane was used. Moreover, scanning electron microscope (SEM) images \\ also provided some evidence related to the tensile properties observed. It \\ can be concluded that the new composite based on NR and TW was \\ successfully prepared with the contribution of a silane coupling agent.
}

Keywords: Natural rubber; Tea waste; Filler; Mechanical properties; Silane

Contact information: a: Department of Rubber Technology and Polymer Science, Faculty of Science and Technology, Prince of Songkla University, Pattani Campus, 94000, Pattani, Thailand; b: School of Materials and Mineral Resources Engineering, Engineering Campus, Universiti Sains Malaysia, 14300, Nibong Tebal, Penang, Malaysia; *Corresponding author: nabil.h@psu.ac.th

\section{INTRODUCTION}

A critical discussion has been taking place concerning natural-based engineering products, and interest in this topic has been spreading globally. This is clearly a response to recent developments concerning renewable resources (Ismail and Haw 2008; Sae-oui et al. 2009; Visakh et al. 2012). The context of sustainable development has been involved throughout the waste disposal strategy, which has aimed to convert worthless materials into a sustainable solution. In preparing rubber products, this term also has been used. Many studies have focused and been conducted on the use of natural fillers in the rubber compounds by both academicians and industrial researchers. One of the waste materials that is abundant is from lignocellulose materials. Studies on the utilization of this material in rubber matrix have been largely explored. For example, Fiorote et al. (2019) tried to modify the cellulose from empty fruit bunch and use it as filler for NR. It was observed that the nanostructured particles of such material were successfully prepared and had shown great effect on the mechanical properties of NR. Cellulose from kenaf fiber was also prepared by Roy and Potiyaraj (2018). It was then compounded with NR to observe the mechanical and thermal properties of the composites. It was clear that the prepared cellulose had a direct effect in enhancing the properties of the composites. 
Tea dust or tea waste (TW) is accumulating as a waste material especially in urban areas due to the global increase in the consumption of tea. It was reported to reach about five million tons per year (Fiorote et al. 2019). This has led to abundant TW. The TW is considered a solid biomass waste and is generally disposed of into the environment. It has not been used for any purpose unless discarded as wet garbage. It also exists in the particulate form and can be further filtered to obtain the finer particles. From this point of view, TW can be advantageous waste if used in the application of rubber materials because it is available for free; it is light weight; and it is rich in polyphenols due to the tannin composed in tea leaves (Utomo and Hunter 2006; Uddin et al. 2009; Song et al. 2019). Although there have been some attempts to utilize it in other industries, such as the textile industry, agricultural applications, and in the production of animal feed, the effective usage of TW is limited and largely unexplored. Moreover, TW consists mainly of lignocellulose, as reported by Bernal et al. (2017). In this respect, the polarity in nature of TW would weaken the interfacial interaction between non-polar NR and TW. The most important factor to obtain the composites with superior reinforcement is to improve the interfacial adhesion and interaction between non-polar and polar components in the composite system (Kushwaha and Kumar 2009). An efficient adhesion across the interface can be obtained at desirable levels.

Silane coupling agents are widely used to improve the performance of incompatible composites. For instance, silane coupling agent has been applied on cellulosic filler to form stable covalent bonds with the rubber matrix (Kushwaha and Kumar 2010). From this point of view, the treatment of TW by silane is expected to change functionality of TW and subsequently enables TW to interact with the rubber matrix. To date, there has been no single attempt to investigate the effects of silanized TW and the properties of NR composites. The summary obtained from this study will provide a new option for the use of TW in rubber compounding. It can also be a source of useful scientific information in creating a new rubber product based on TW filled NR composites. Such rubber product can be more beneficial in terms of cost and environmental aspects from TW mixed NR.

\section{EXPERIMENTAL}

\section{Materials}

Table 1 lists the mixing formulation implemented in this work. The SMR 20 grade was supplied by Mardec Berhad (Selangor, Malaysia).

Table 1. Compounding Ingredients for Preparing the NR/TW Composites with and Without Silane Coupling Agent

\begin{tabular}{|c|c|c|}
\hline Ingredients & $\begin{array}{c}\text { Without Si69 (part per hundred } \\
\text { parts of rubber or phr) }\end{array}$ & $\begin{array}{c}\text { With Si69 } \\
\text { (phr) }\end{array}$ \\
\hline SMR 20 & 100 & 100 \\
\hline Zinc oxide & 1.5 & 1.5 \\
\hline Stearic acid & 1.5 & 1.5 \\
\hline CBS & 1.9 & 1.9 \\
\hline Vulkanox BKF & 2.0 & 2.0 \\
\hline Sulfur & 1.6 & 1.6 \\
\hline TESPT & - & 1.0 \\
\hline TW powder & 0 to 15 & 0 to 15 \\
\hline
\end{tabular}


The tea waste (TW) powder was supplied by Gold Leaf Marketing Sdn. Bhd (Penang, Malaysia). Other additives were purchased from Bayer (M) Ltd. (Selangor, Malaysia), including silane coupling agent: bis(triethoxysilylpropyl)tetrasulfide (TESPT) or Si69; activators: zinc oxide and stearic acid; while N-cyclohexyl-2-benzothiazolesulfenamide (CBS) and 2,2 methylene-bis-(4-methyl-6-tert-butylphenol) (Vulkanox BKF) were used as accelerator and antioxidant, respectively, and sulfur was used as vulcanizing agent.

\section{Preparation of TW Powder}

The TW collected in this study was fresh TW. It was ground into powder form, prior to being used, by means of a Table Type Pulverizing Machine from Rong Tsong Precision Technology Co., Ltd. (Dali District, Taichung City, Taiwan). The powder was then sieved to gain the final size (below $100 \mu \mathrm{m}$ in size). The TW powder was dried in a vacuum oven at $105^{\circ} \mathrm{C}$ for $2 \mathrm{~h}$ to expel moisture. Dried TW powder was used in rubber compounding without further treatment. Figure 1 shows the scanning electron microscope (SEM) image of TW at magnification of 50×. From the figure, it can be seen that the TW was irregularly shaped and varied in size and length. The particle size of TW was less than $200 \mu \mathrm{m}$ as observed in the SEM micrograph.

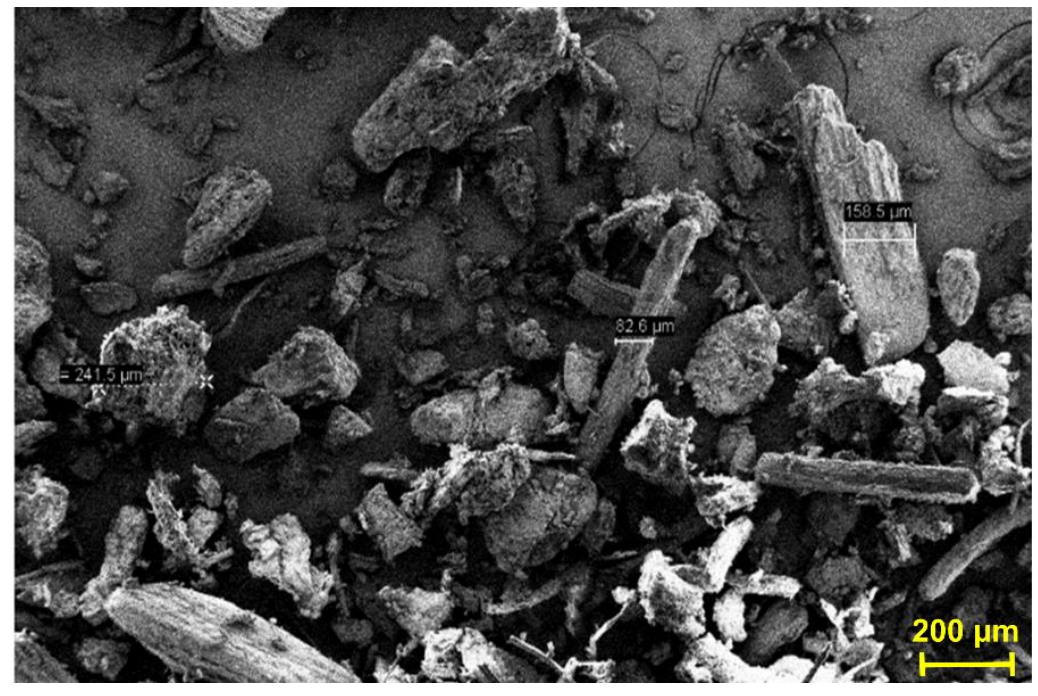

Fig. 1. SEM image of TW powder at magnification of $50 x$

\section{Compounding and Vulcanization Step}

The compounding of NR, TW, and other additives including TESPT, $\mathrm{ZnO}$, stearic acid, CBS, BKF, and sulfur, were done on a laboratory-size $\left(160 \times 320 \mathrm{~mm}^{2}\right.$ model XK160) two-roll mill (Shanghai Rubber Machinery Works, Shanghai, China) at ambient temperature for $20 \mathrm{~min}$. The curing times of the compounds were measured using a Monsanto Moving Die Rheometer (MDR 2000) (Alpha Technologies, Hudson, OH, USA) at $150{ }^{\circ} \mathrm{C}$, which was used to determine scorch time $\left(t_{\mathrm{s}}\right)$, curing time $\left(t \mathrm{c}_{90}\right)$, and torques according to ASTM D5289 (2019). Samples of the respective curing times were subsequently compression molded using a stainless steel mold at $150{ }^{\circ} \mathrm{C}$ with a force of 10 MPa using a laboratory hot-press (GT-7014-A30C; Gotech Testing Machines Inc., Taichung City, Taiwan). 


\section{Tensile Properties}

The rubber vulcanizates were first cut into dumbbell shape using a Wallace die cutter (H.W. Wallace \& Co., Ltd., Surrey, UK) before proceeding to tensile testing. The tensile test was conducted using an Instron machine model 3366 (Instron Corporation, Norwood, MA, USA) following ASTM D412 (2016) with a crosshead speed of 500 $\mathrm{mm} / \mathrm{min}$. From this test, the tensile properties, such as tensile strength, modulus at specific strain, and elongation at break, were obtained and recorded.

\section{Thermo-oxidative Aging}

The thermal stability of the composites was evaluated through thermal aging. The dumbbell-shaped specimens were placed in an air circulating oven at a temperature of 100 ${ }^{\circ} \mathrm{C}$ for $48 \mathrm{~h}$, according to ASTM D573. The aging property was predicted from the retention of tensile properties where it was calculated based on the Eq. (1).

$$
\text { Retention }=\frac{\text { Value after aging }}{\text { Value before aging }} \times 100
$$

\section{Rubber-filler Interactions}

A vulcanized rubber piece was cut into a rectangular shape of $30 \mathrm{~mm} \times 5 \mathrm{~mm} \times 2$ $\mathrm{mm}$ for every formulation. The sample was then swollen in toluene inside a closed bottle for $72 \mathrm{~h}$ at room temperature. Afterwards, the sample was taken out, wiped quickly and weighed. The sample was dried and weighed again. Calculation of rubber-filler interaction was based on the Lorenz and Park's equations that are given below (Lorenz and Park 1961),

$$
\frac{Q_{\mathrm{f}}}{Q_{\mathrm{g}}}=a e^{-z}+b
$$

where the subscripts $f$ and $g$ are respectively referred to as the filled and gum vulcanizates, $Z$ is the ratio by weight of filler to rubber hydrocarbon in the vulcanizates, $a$ and $b$ are constants. If $Q_{\mathrm{f}} / Q_{\mathrm{g}}$ has the higher value, it means that the extent of interaction between filler and matrix is lower.

$Q$, the weight of swelling per gram of NR, was calculated by using Eq. 3:

$$
Q=\frac{\text { Swollen weight }- \text { Dried weight }}{\text { Originial weight } \times \frac{100}{\text { Formula weight }}}
$$

\section{Scanning Electron Microscopy}

The morphological properties for the sample of tensile fractured surface and TW were studied by using scanning electron microscopy (SEM) (Zeiss Supra-35VP; Carl Zeiss AG, Oberkochen, Germany). The samples from the broken tensile testing were collected and cut. The vulcanizates rubber sample and the TW were then sputter-coated (TMAXSputtering1; Xiamen Tmax Battery Equipments Limited, Fujian, China) with a thin layer of gold to avoid electrostatic changing and poor image resolution.

\section{Fourier Transform Infrared (FTIR) Spectroscopy Analysis}

The functionalities of TW were detected using Fourier transform infrared spectroscopy (Perkin Elmer System 2000; PerkinElmer Inc., Waltham, MA, USA). The FTIR spectrum was obtained in the wavenumber range of 550 to $4000 \mathrm{~cm}^{-1}$. The TW was ground with potassium bromide $(\mathrm{KBr})$ for the formation of pellet that was used to obtain the infrared spectrum. 


\section{Fatigue Life}

The rubber sheet was used to prepare the samples. It was cut into rectangular sheets $(22.9 \mathrm{~cm} \times 7.6 \mathrm{~cm} \times 0.15 \mathrm{~cm})$. Each sample was cut at right angles using a BS type E dumbbell cutter. The Fatigue tests of the vulcanizates were then carried out on a Monsanto Fatigue to Failure Tester (FTFT). To avoid the hysteresis effect, the samples were extended at the ratio of 1.61 and subjected to repeated cyclic strain at $100 \mathrm{cpm}$ prior to test. The sample was extended at the extension ratio of 1.61. The numbers of cycles were recorded automatically. The fatigue life in kilocycles for each sample was calculated as the JIS (Japanese Industrial Standard) average according to the equation below;

$$
\text { JIS average }=0.5 \mathrm{~A}+0: 3 \mathrm{~B}+0.1(\mathrm{C}+\mathrm{D})
$$

where A is the highest value followed by $\mathrm{B}, \mathrm{C}$, and $\mathrm{D}$

\section{Dynamic Properties}

The extent of interaction between rubber and filler of the TW filled NR composites with and without silane was monitored through the dynamic properties. Testing was carried out on a Rubber Process Analyzer model D-RPA 3000 (MonTech Werkstoffprüfmaschinen $\mathrm{GmbH}$, Buchen, Germany). The sample was first cured at $150{ }^{\circ} \mathrm{C}$ depending on its own curing time obtained from similar RPA. The sample was then cooled to $60{ }^{\circ} \mathrm{C}$. Finally, the dynamic properties were tested at a frequency of $10 \mathrm{~Hz}$ and strains in the range of 0.56 to $90 \%$. The storage shear modulus $\left(G^{\prime}\right)$ was recorded to determine the rubber-filler interaction. The rubber-filler interaction was evaluated from the Payne effect which can be calculated as follows,

$$
\text { Payne effect }=G^{\prime}{ }_{i}-G_{f}^{\prime}
$$

where $G_{i}^{\prime}$ is the $G^{\prime}$ at $0.5 \%$ strain and $G_{f}^{\prime}$ is the $G^{\prime}$ at $90 \%$ strain. Lower Payne effect indicates higher extent of rubber-filler interaction.

\section{RESULTS AND DISCUSSION}

\section{FTIR Analysis}

As shown in Fig. 2, there were some interesting absorbance peaks observed, especially at wavenumbers of 3298, 2993, 1620, and $1032 \mathrm{~cm}^{-1}$. A broad band at a wavenumber of $3298 \mathrm{~cm}^{-1}$ corresponds to $\mathrm{O}-\mathrm{H}$ stretching obtained from the presence of alcohols and phenols in the TW. The peak at $2993 \mathrm{~cm}^{-1}$ (medium) is due to the C-H stretch of TW. Another interesting peak is the amine group in the form of $\mathrm{N}-\mathrm{H}$ bend and $\mathrm{C}-\mathrm{N}$ stretch (aliphatic amines); these were observed at the wavenumbers of $1620 \mathrm{~cm}^{-1}$ and 1032 $\mathrm{cm}^{-1}$ respectively. The peaks observed were in good agreement to the previous work reported by Uddin et al. (2009) and Tian et al. (2016).

\section{Curing Characteristics}

Table 2 lists the results obtained from the MDR 2000 of the TW filled NR composites with and without silane coupling agent. It was observed that the maximum torque $\left(M_{\mathrm{H}}\right)$ increased with increased TW contents. The $M_{\mathrm{H}}$ value is defined as a shear modulus of the fully cured rubber (Nabil and Ismail 2014). The enhanced torque values confirmed that the processing of NR compounds characterized by a higher amount of TW became harder, which decreased the movement of rubber chain and the flexibility of chain 
and thus allowed the increase of the $M_{\mathrm{H}}$ value. In the presence of silane coupling agent, the $M_{\mathrm{H}}$ was higher than that of composites without silane. Better interfacial adhesion between TW and the interface of rubber matrix may contribute to an enhancement of the shear modulus of the composites. The possible interaction of this composite in the presence of silane is discussed later.

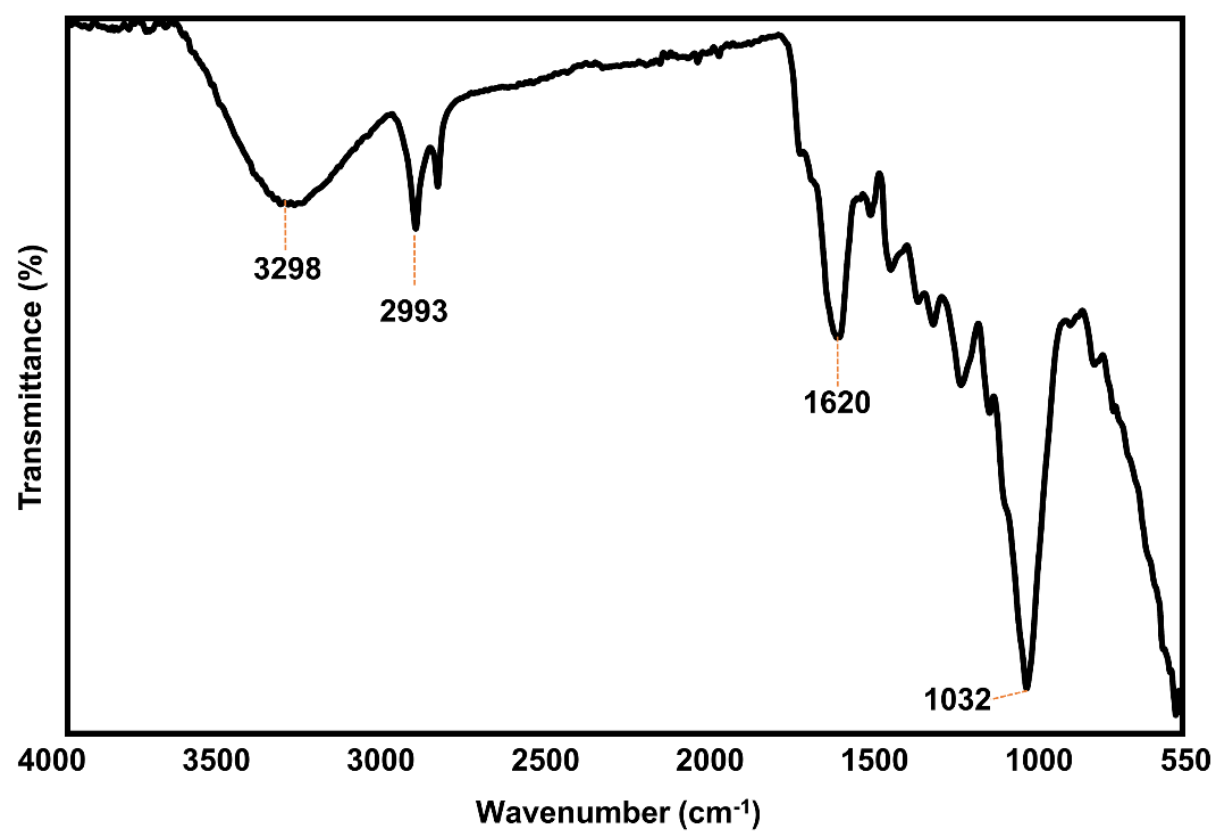

Fig. 2. FTIR spectrum of TW powder

Table 2. Curing Properties Obtained from Curing Curves of the NR/TW Composites with and without Silane Coupling Agent

\begin{tabular}{|c|c|c|c|c|c|c|}
\hline \multirow{2}{*}{$\begin{array}{l}\text { TW Content } \\
\text { (phr) }\end{array}$} & \multicolumn{2}{|c|}{$M_{H}(\mathrm{dNm})$} & \multicolumn{2}{|c|}{$t s_{2}$ (min) } & \multicolumn{2}{|c|}{$t c_{90}(\min )$} \\
\hline & $\begin{array}{l}\text { Without } \\
\text { Si69 }\end{array}$ & $\begin{array}{l}\text { With } \\
\text { Si69 }\end{array}$ & $\begin{array}{c}\text { Without } \\
\text { Si69 }\end{array}$ & $\begin{array}{l}\text { With } \\
\text { Si69 }\end{array}$ & $\begin{array}{c}\text { Without } \\
\text { Si69 }\end{array}$ & $\begin{array}{l}\text { With } \\
\text { Si69 }\end{array}$ \\
\hline 0 & 5.21 & & 3.25 & & 5.37 & \\
\hline 5 & 5.27 & 5.42 & 3.10 & 2.42 & 4.35 & 4.28 \\
\hline 10 & 5.33 & 5.53 & 2.60 & 2.41 & 3.58 & 3.48 \\
\hline 15 & 5.56 & 5.7 & 2.49 & 2.39 & 3.56 & 3.45 \\
\hline
\end{tabular}

Scorch time $\left(t \mathrm{~s}_{2}\right)$ and curing time $\left(t \mathrm{c}_{90}\right)$ showed a decreasing trend over the TW contents. The $t_{2} 2$ is the time where the vulcanization starts and $t_{90}$ is the time within which the vulcanization reaches $90 \%$. As shown in the FTIR spectrum of TW, an amine group available in TW was the main reason to fasten curing process. Coran 2003 and Surya et al. 2013 have reported that an alkalinity of additive plays very important role to enhance the cure rate. Any chemical substance that increases the $\mathrm{pH}$ of the system would lead to a speeding up of the curing process. Therefore, it was expected that the amine content in TW can accelerate the curing rate of the composites. It was noteworthy that shorter $t \mathrm{~s}_{2}$ and $t \mathrm{c}_{90}$ were found in NR composites with silane. This could be attributed to the ability of silane to improve the dispersion of TW particles throughout the rubber matrix. Another probable reason might have been due to the functionality of silane itself that tended to reduce the 
polarity of TW. Then, it can reduce the adsorption of accelerator to the TW surface and therefore quicken the vulcanizing process of the NR compounds.

\section{Tensile Properties}

Table 3 shows the tensile properties of NR composites with and without silane coupling agent. The tensile strength of the NR composites decreased as the TW loading increased. This could have been due to the incompatibility or poor adhesion between the TW and matrix of rubber. Upon inclusion of silane coupling agent, it is clear that higher tensile strength was observed, which was responsible for the better rubber-filler interaction. This showed that the efficiency of silane in coupling with TW was remarkably superior in comparison to the composites without silane. There are two reaction mechanisms taking place in the presence of silane (Sengloyluan et al. 2014). These mechanisms are temperature-dependent and may have occurred during compound mixing or during compression molding.

Table 3. Unaged and Aged Tensile Strength and Elongation at Break of the NR/TW Composites with and without Silane Coupling Agent

\begin{tabular}{|c|c|c|c|c|}
\hline \multirow{2}{*}{$\begin{array}{c}\text { TW Content } \\
\text { (phr) }\end{array}$} & \multicolumn{2}{|c|}{ Tensile Strength (MPa) } & Elongation at Break (\%) \\
\cline { 2 - 5 } & Without Si69 & With Si69 & Without Si69 & With Si69 \\
\hline Before Aging & \multicolumn{4}{|c|}{} \\
\hline 0 & $17.4 \pm 0.49$ & & $958.9 \pm 10.51$ & \\
\hline 5 & $16.6 \pm 0.55$ & $17.0 \pm 0.57$ & $902.8 \pm 9.87$ & $890.0 \pm 8.52$ \\
\hline 10 & $15.1 \pm 0.25$ & $16.7 \pm 0.81$ & $878.9 \pm 7.22$ & $852.2 \pm 7.78$ \\
\hline 15 & $14.1 \pm 0.44$ & $14.6 \pm 0.49$ & $848.9 \pm 9.83$ & $751.7 \pm 10.11$ \\
\hline After Aging & $13.1(74.7)$ & & $498.5(52.0)$ & \\
\hline 0 & $12.5(75.3)$ & $14.1(82.9)$ & $485.2(53.7)$ & $475.1(53.4)$ \\
\hline 5 & $11.5(76.2)$ & $13.9(83.2)$ & $473.5(53.8)$ & $457.4(53.7)$ \\
\hline 10 & $11.0(78.1)$ & $12.5(85.6)$ & $459.4(54.1)$ & $432.3(57.5)$ \\
\hline 15 & &
\end{tabular}

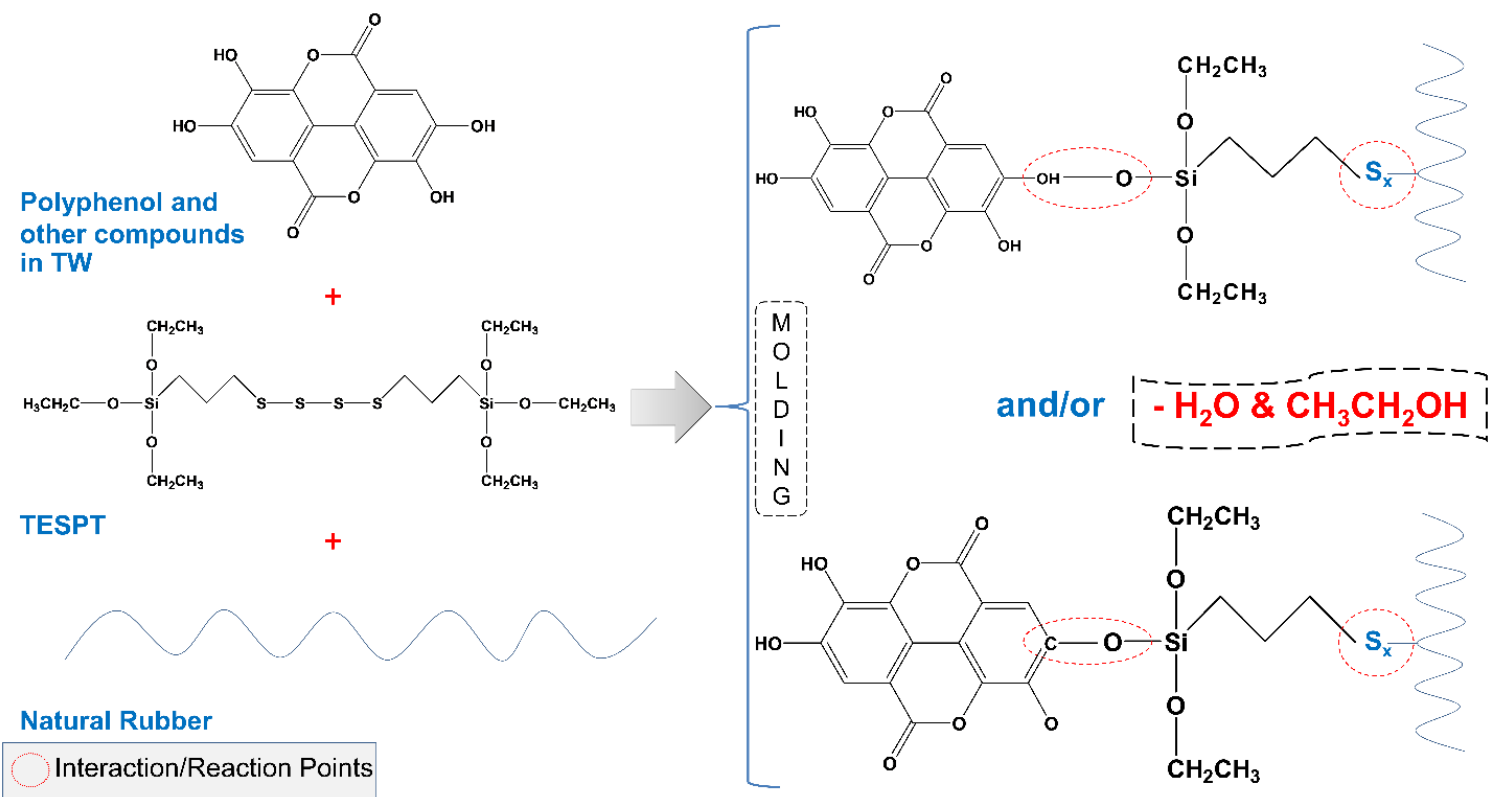

Fig. 3. Proposed mechanism of the NR/TW composites in the presence of silane coupling agent 
Figure 3 illustrates a possible mechanism obtained from this composite. The mechanism is possible through (1) the silane-to-TW or silanization/ hydrophobation reaction and (2) the silane-to-rubber or coupling reaction. In addition, the silanization reaction of the composites can be formed either through hydrogen bonding and/or chemical bonding that occur during mixing or compression molding.

A similar finding was also observed for the elongation at break of the composites. When TW was added, the unstrained particle of TW led to the formation of aggregates in between the chains of flexible rubber and restricted the mobility. The addition of filler may reduce the elasticity of the composites; higher TW loading caused a stiffer NR composite. As expected, the elongation at break of the composites with silane coupling agent was lower compared to untreated counterparts because of the better rubber-filler interaction. Such finding corresponded to the stress at 100\% (M100) and 300\% (M300) strains seen in Table 4. When more TW was put into the NR matrix, the composites became stiffer, the macromolecular chains of the rubber had difficulty moving because of the restriction to the deformation, hence increasing the tensile modulus. The presence of silane coupling agents led to a better improvement in the modulus due to the corresponding rubber-filler interfacial bonding. This will clearly result in an increase in the efficiency of stress transfer from the matrix to the filler, which consequently led to a higher modulus.

Table 4. Unaged and Aged Tensile Modulus of the NR/TW Composites with and Without Silane Coupling Agent

\begin{tabular}{|c|c|c|c|c|}
\hline \multirow{2}{*}{$\begin{array}{c}\text { TW Content } \\
\text { (phr) }\end{array}$} & \multicolumn{2}{|c|}{ M100 (MPa) } & \multicolumn{2}{|c|}{ M300 (MPa) } \\
\hline & Without Si69 & With Si69 & Without Si69 & With Si69 \\
\hline \multicolumn{5}{|l|}{ Before Aging } \\
\hline 0 & $0.51 \pm 0.01$ & - & $1.29 \pm 0.09$ & - \\
\hline 5 & $0.56 \pm 0.02$ & $0.82 \pm 0.01$ & $1.51 \pm 0.07$ & $2.02 \pm 0.06$ \\
\hline 10 & $0.66 \pm 0.02$ & $0.88 \pm 0.03$ & $1.60 \pm 0.08$ & $2.08 \pm 0.11$ \\
\hline 15 & $0.79 \pm 0.01$ & $1.11 \pm 0.04$ & $1.74 \pm 0.04$ & $2.46 \pm 0.03$ \\
\hline \multicolumn{5}{|l|}{ After Aging } \\
\hline 0 & $0.60(117.6)$ & - & $1.39(107.7)$ & - \\
\hline 5 & $0.65(116.1)$ & $0.92(112.2)$ & $1.61(106.6)$ & $2.12(104.9)$ \\
\hline 10 & $0.76(115.1)$ & $0.98(111.4)$ & $1.71(106.3)$ & $2.18(104.8)$ \\
\hline 15 & $0.90(113.9)$ & $1.23(110.8)$ & $1.84(105.7)$ & $2.56(104.1)$ \\
\hline
\end{tabular}

\section{Thermo-oxidative Aging}

The tensile properties of the samples after thermal aging are listed in Tables 3 and 4. As for the tensile strength and elongation at break (Table 3), it is clearly shown that these two values decreased after thermal aging. Such reduction could be due to the oxidation of the rubber molecule, which resulted from chain scissions. Scission of the larger molecular chains created a number of shorter chains, leading to a reduction in tensile strength and elongation at break. To evaluate further on the thermal stability of the composites, the retention of these two results were also calculated (see the values in the brackets), e.g. retained elongation. The retained tensile strength and elongation at break did not significantly vary over the loadings of TW. The phenolic contained in TW may be attributed to slower degradation of rubber composites. It can act as natural antioxidant to the rubber composite. Generally, NR is easily broken due to degradation of isolated double bonds, leading to the abstraction of active $\alpha$-hydrogen, thus producing alkyl radicals, peroxyl radicals and other free radicals (Lu et al. 2020). The role of antioxidant is to capture these free radicals, preventing them from contributing to progressive interaction. The 
phenolic contains an $\mathrm{O}-\mathrm{H}$ bond in which the free energy of dissociation is lower than $\alpha$ hydrogen bond dissociation in NR. From this point of view, the antioxidant can preferentially dissociate first and effectively inhibit the oxidation of NR. In addition to this, treating TW with silane conferred superior thermal stability on the composites. When the TW was modified, the interfacial combination between NR and TW was improved, and the thermal was found to be higher for composites containing silane coupling agent.

Tensile modulus (M100) values of the composites before and after thermooxidative ageing are listed in Table 4. The modulus aged composites increased with increasing TW content. This was attributed to the additional crosslinks formed by several free radicals. A high rate of radical termination in the bulk of rubber has brought to increase the crosslinks after thermal aging (Rabello and White 1997).

\section{Rubber-filler Interaction}

As shown from the tensile strength, inclusion of TW to the NR matrix influenced the tensile strength of the composites due to its poor distribution of TW throughout the rubber matrix. To confirm such observation, the rubber-filler interaction of TW filled NR composites was also evaluated, where the results were monitored through the values of $Q_{\mathrm{f}} / Q_{\mathrm{g}}$ and dynamic properties. The value of $Q_{\mathrm{f}} / Q_{\mathrm{g}}$ (Fig. 4.) slightly increased with increasing TW contents.

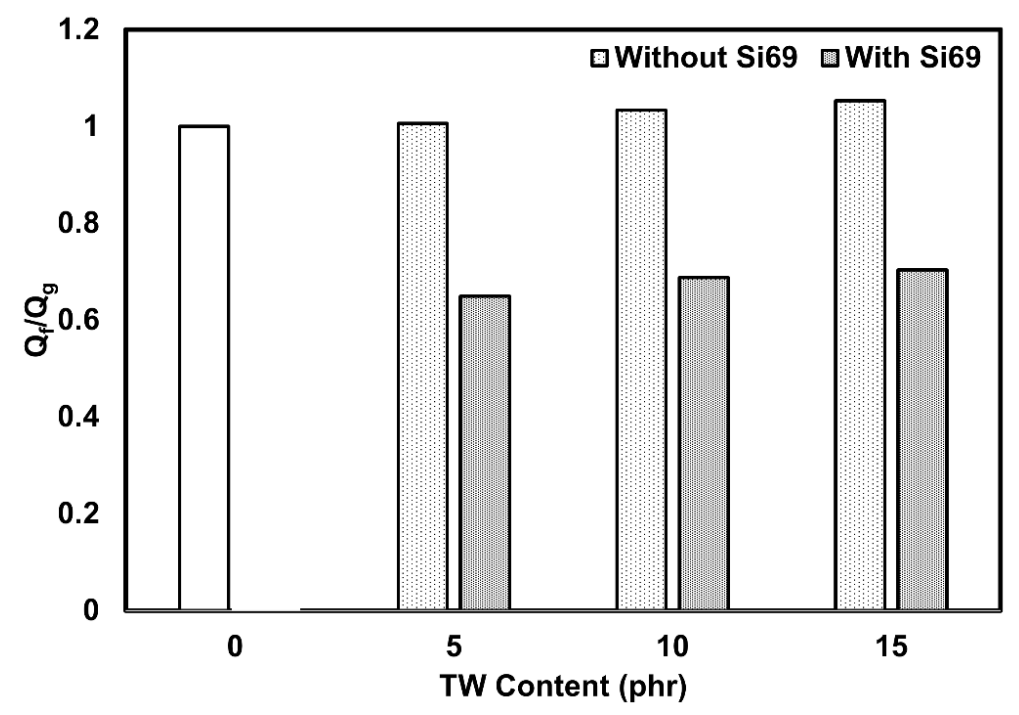

Fig. 4. $Q_{t} / Q_{g}$ values of NR/TW composites with and without silane coupling agent

It is widely known that the higher value of $Q_{\mathrm{f}} / Q_{\mathrm{g}}$, the extent of interaction between rubber and filler is lower. It can be concluded that the NR composites that contain higher loading of TW have the weaker interaction between rubber and filler. Treating the TW with silane resulted in a strong interaction between TW and the rubber matrix. From the $Q_{\mathrm{f}} / Q_{\mathrm{g}}$ values, it was evidently shown that it corresponded to the tensile strength, elongation at break, and tensile modulus observed in the preceding session, indicating that strong rubberfiller interaction was observed at the certain amount of TW and after introducing the silane coupling agent. The observed higher rubber-filler interaction was simply because the silane coupling agent was present at the interface. Consequently, TW had high affinity with NR, as proposed in Fig. 3. Correlation between $Q_{\mathrm{f}} / Q_{\mathrm{g}}$ values and respective tensile properties is discussed elsewhere (Mathialagan and Ismail 2012; Hayeemasae and Ismail 2019). 
Figure 5 exhibits the storage shear modulus $\left(G^{\prime}\right)$ over the applied strain. It shows that $G$ ' of unfilled NR showed constant values at very low strain but gradually decreased when the strain is over $50 \%$. This was simply because of molecular stability of viscoelastic material. However, nonlinear viscoelastic behavior was captured for TW filled NR composites, where $G$ ' increased as a function of TW content. This may be due to the presence of a filler network. Also, $G$ ' decreased at high strain and kept decreasing till minimum. Higher strain has high tendency to break filler network. Such filler-filler network can be further seen from the result of Payne effect (Fig. 6).

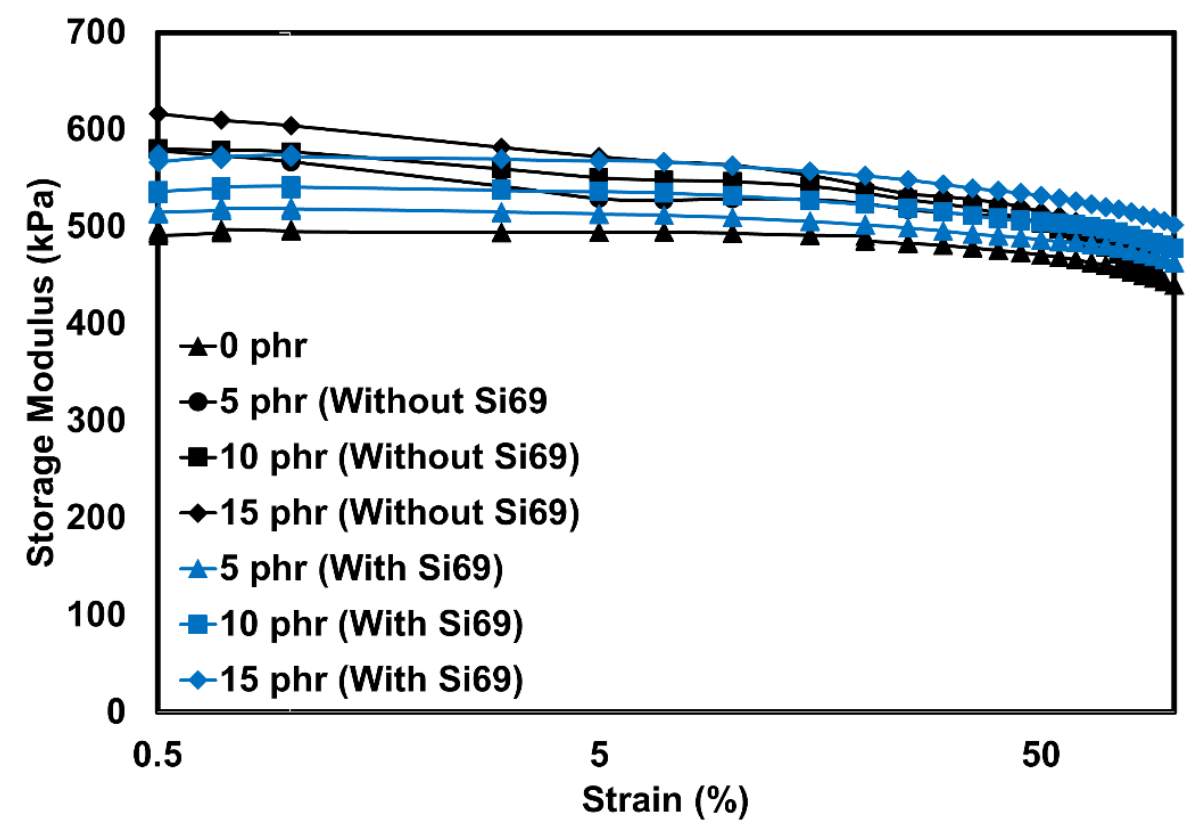

Fig. 5. Storage modulus as a function of strain of NR/TW composites with and without silane coupling agent

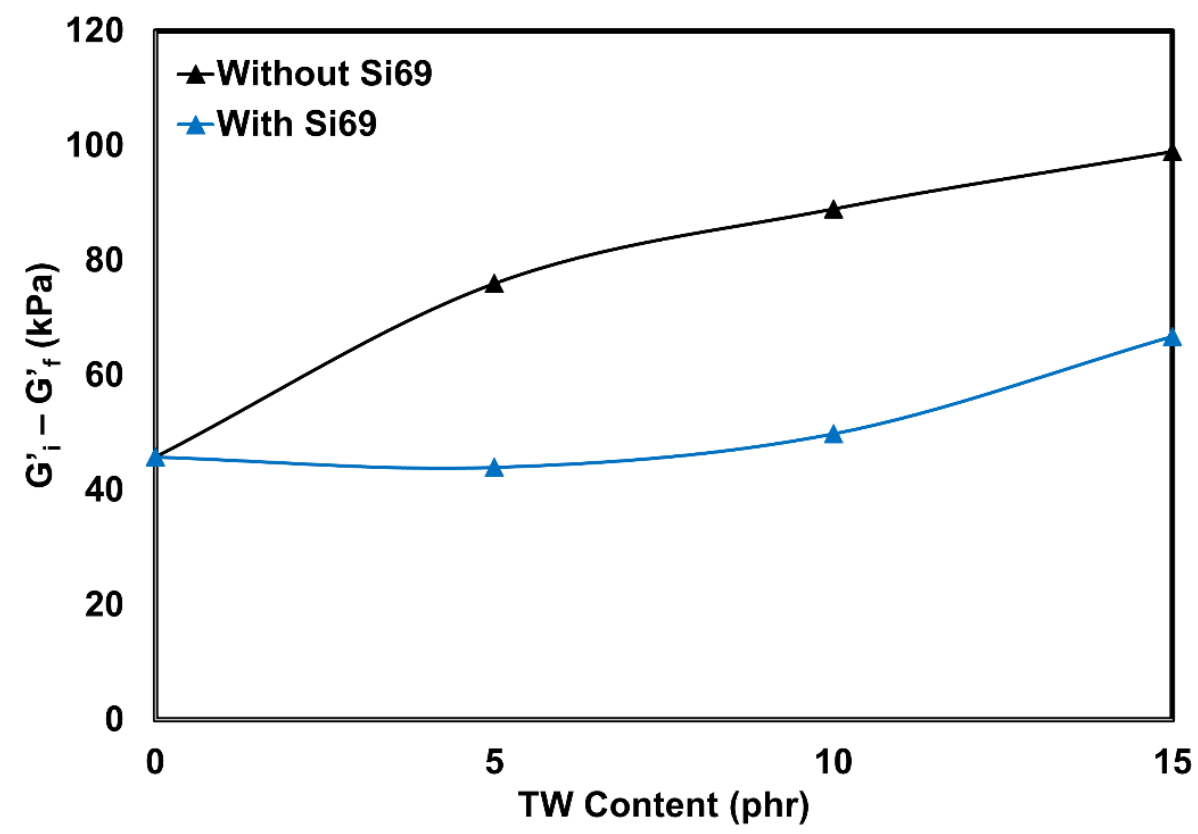

Fig. 6. Payne effect of NR/TW composites with and without silane coupling agent 
The level of $G^{\prime}{ }_{i}-G^{\prime} f$ was found to be higher over the TW content. Increasing these values is attributed to formation of filler-filler interaction. Such interaction became stronger at higher content of TW due to the agglomerating effect, which was discussed in the later session. Furthermore, it is interesting to highlight that treating TW by silane brought about a reduction in the filler-filler network. As can be seen from the Payne effect, a lower level of $G^{\prime}{ }_{i}-G^{\prime}{ }_{f}$ was found for such composites. A reduction of Payne effect was mainly attributed to better rubber-filler interaction. The Payne effect result correlated well to the tensile strength of the composites.

\section{Fatigue Life}

The fatigue life of NR composites with and without silane coupling agent is shown in Fig. 7. It can be observed that fatigue life decreased with increasing TW content. Incorporating the particulate filler in flexible rubber resulted in the friction of TW particles and rubber surface. This will create a crack at the rubber-filler interphase, resulting in catastrophic failure. As more TW content is loaded, TW particles or aggregates may not disperse well. This defect can act as stress concentration area and lowering the fatigue life under dynamic condition (Ismail et al. 2007). It was also shown that the fatigue life of composites containing silane coupling agent was higher than the composites with silane coupling agent. This phenomenon may be responsible to the better rubber-filler interaction as discussed earlier. Such a point of interaction acts as a hook to pull the surrounding rubber chains while stretching or while fatigue testing. Strain-induced crystallization was promoted faster, which led to improve fatigue life.

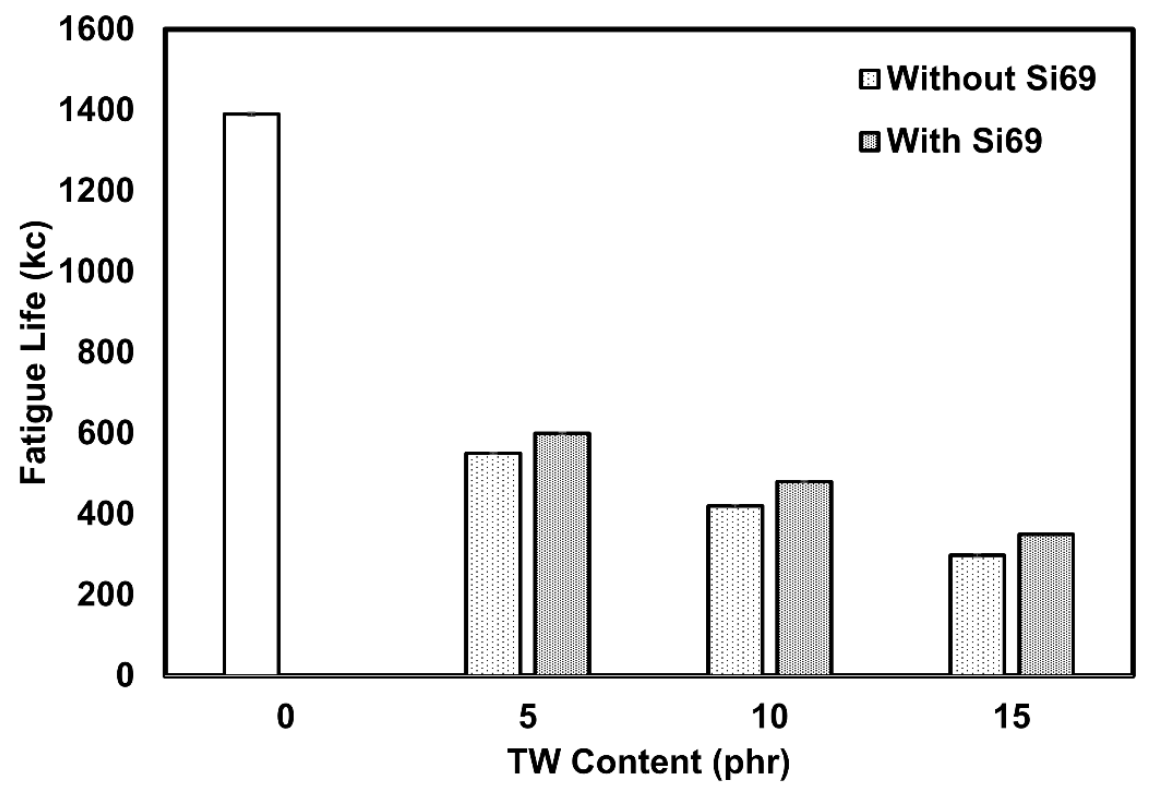

Fig. 7. Fatigue life of NR/TW composites with and without silane coupling agent

\section{Morphological Characteristics of the Composites}

Figure 8 shows the SEM images of TW-filled NR composites with and without silane coupling agent. Considering the unfilled NR $(0 \mathrm{phr})$, the morphology was more towards a flat and smooth surface due to the absence of filler in the matrix. However, when more TW was mixed into the matrix, i.e., 5 and $15 \mathrm{phr}$, it revealed that with increasing TW contents, the fracture of composites became rougher. It was also apparent that there was an 
evidence of filler agglomeration and uneven distribution of TW in the matrix of rubber. Apart from that, the images showed many TW pullouts from the matrix of rubber and some cavities were noticed. This was because of the poor adhesion between irregular shaped TW particles and the matrix of rubber that caused the TW to be pulled out from the rubber easily when stress was applied, hence leaving the gaping holes. This correlated to the lower tensile strength observed in the preceding session.

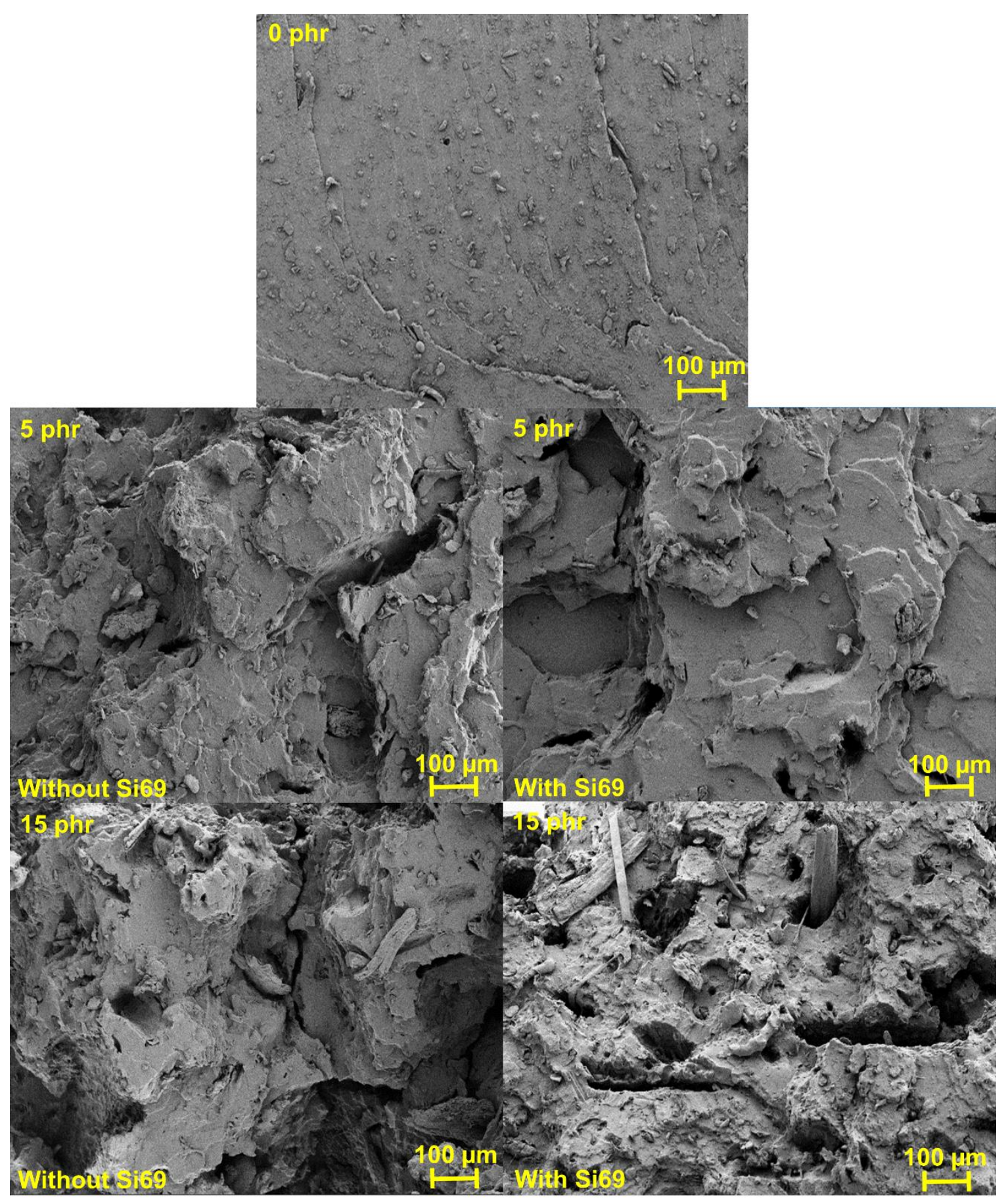

Fig. 8. SEM images at the magnification of $100 \times \mathrm{NR} / \mathrm{TW}$ composites with and without silane coupling agent 
Upon treatment by silane coupling agent, lower TW pullouts were presented as TW loading increased. An augmentation in surface roughness also occurred as well, compared to the fractured surface of the composites without silane coupling agent, which showed less tearing lines, leading to lower ultimate tensile value. Better homogeneity in TW-filled NR composites indicated a coherence of the TW and the NR phases. More uniform distribution of TW improved the stress-transfer, which led to resistance from crack propagation and hence resulted in higher tensile strengths. Such explanation is also in good agreement to the work reported elsewhere (Sae-Oui et al. 2002; Sahakaro and Beraheng 2008), who observed the same morphology upon the addition of silane coupling agent and hence resulted in enhanced mechanical properties of the composites

\section{CONCLUSIONS}

1. Treating the TW with silane coupling agent greatly influenced the overall properties of the composites. It quickened the curing process due to its ability to reduce to possible adsorption of accelerator by TW.

2. Better interaction between TW and rubber matrix was observed, as shown from the $M_{\mathrm{H}}$ and tensile properties of the composites. When silane was used, there were two reaction mechanisms competitively taking place during compound mixing or during compression moulding. These are the silane-to-TW or silanization/hydrophobation reaction and the silane-to-rubber or coupling reaction.

3. The results obtained from the tensile properties are in good agreement with the $Q_{\mathrm{f}} / Q_{\mathrm{g}}$ values and Payne effect, indicating better rubber-filler interaction when silane was used.

4. The SEM images also provided some evidence relating to the tensile properties observed. Upon treatment with silane coupling agent, an augmentation in surface roughness was seen and lower TW pullouts were presented as TW loading increased.

\section{ACKNOWLEDGEMENTS}

The authors would like to thank the Faculty of Science and Technology, at the Prince of Songkla University and School of Materials and Mineral Resources Engineering, Universiti Sains Malaysia for providing the materials and facilities to complete this project.

\section{REFERENCES CITED}

ASTM D412 (2016). "Standard test methods for vulcanized rubber and thermoplastic elastomers-tension," ASTM International, West Conshohocken, PA, USA.

ASTM D5289 (2019). "Standard test method for rubber property-vulcanization using rotorless cure meters," ASTM International, West Conshohocken, PA, USA. ASTM D573 (2019). "Standard Test Method for Rubber-Deterioration in an Air Oven," ASTM International, West Conshohocken, PA, USA. 
Bernal, M. P., Sommer, S. G., Chadwick, D., Qing, C., Guoxue, L., and Michel, F. C. (2017) "Current approaches and future trends in compost quality criteria for agronomic, environmental, and human health benefits," in: Advances in Agronomy, D. L. Sparks (ed.), Academy Press, Cambridge, MA, USA, pp. 143-233.

Coran, A. (2003). "Chemistry of the vulcanization and protection of elastomers: A review of the achievements," Journal of Applied Polymer Science 87(1), 24-30. DOI: 10.1002/app.11659

Fiorote, J. A., Freire, A. P., De Sousa Rodrigues, D., Martins, M. A., Andreani, L., and Valadares, L. F. (2019). "Preparation of composites from natural rubber and oil palm empty fruit bunch cellulose: Effect of cellulose morphology on properties," BioResources 14(2), 3168-3181. DOI: 10.15376/biores.14.2.3168-3181

Hayeemasae, H., and Ismail, H. (2019). "Reinforcement of epoxidized natural rubber through the addition of sepiolite," Polymer Composites 40(3), 924-931. DOI: $10.1002 / \mathrm{pc} .24762$

Ismail, H., and Haw, F. (2008). "Effects of palm ash loading and maleated natural rubber as a coupling agent on the properties of palm-ash-filled natural rubber composites," Journal of Applied Polymer Science 110(5), 2867-2876. DOI: 10.1002/app.28844

Ismail, H., Arjulizan, R. and Azura, A. R. (2007). "Study of fatigue life and filler interaction of paper sludge filled epoxidized natural rubber (ENR) and maleated natural rubber," Journal of Polymers and Environment 15, 67-74. DOI: 10.1007/s10924-006-0043-2

Kushwaha, P. K., and Kumar, R. (2009). "Effect of silanes on mechanical properties of bamboo fiber-epoxy composites," Journal of Reinforced Plastics and Composites 29(5), 718-724. DOI: 10.1177/0731684408100691

Kushwaha, P. K., and Kumar, R. (2010). "Studies on water absorption of bamboo-epoxy composites: Effect of silane treatment of mercerized bamboo," Journal of Applied Polymer Science 115(3), 1846-1852. DOI: 10.1002/app.31317

Lorenz, O., and Parks, C. (1961). "The crosslinking efficiency of some vulcanizing agents in natural rubber," Journal of Polymer Science 50(154), 299-312. DOI: 10.1002/pol.1961.1205015404

Lu, L., Kaiqiang, L., Wei, Y., Sidian, Z., Wencai, W., Haiyan, X., and Sizhu, W. (2020). "Insight into the anti-aging mechanisms of natural phenolic antioxidants in natural rubber composites using a screening strategy based on molecular simulation." RSC Advances 10(36), 21318-21327. DOI: 10.1039/D0RA03425H

Mathialagan, M., and Ismail, H. (2012). "Optimization and effect of 3-aminopropyltriethoxysilane content on the properties of bentonite-filled ethylene propylene diene monomer composites," Polymer Composites 33(11), 1993-2000. DOI: $10.1002 /$ pc. 22340

Nabil, H., and Ismail, H. (2014). "Blending of natural rubber/recycled ethylenepropylene-diene rubber: Promoting the interfacial adhesion between phases by natural rubber latex," International Journal of Polymer Analysis and Characterization 19(2), 159-174. DOI: 10.1080/1023666X.2014.873597

Rabello, M., and White, J. (1997). "Photodegradation of polypropylene containing a nucleating agent," Journal of Applied Polymer Science 64(13), 2505-2517. DOI: 10.1002/(SICI)1097-4628(19970627)64:13<2505::AID-APP4>3.0.CO;2-H

Roy, K., and Potiyaraj, P. (2018). "Development of high performance microcrystalline cellulose based natural rubber composites using maleated natural rubber as compatibilizer," Cellulose 25, 1077-1087. DOI: 10.1007/s10570-017-1613-2 
Sae-Oui, P., Rakdee, C., and Thanmathorn, P. (2002). "Use of rice husk ash as filler in natural rubber vulcanizates: In comparison with other commercial fillers," Journal of Applied Polymer Science 83(11), 2485-2493. DOI: 10.1002/app.10249

Sae-Oui, P., Sirisinha, C., and Thaptong, P. (2009). "Utilization of limestone dust waste as filler in natural rubber," Journal of Material Cycles and Waste Management 11, 166-171. DOI: 10.1007/s10163-008-0230-4

Sahakaro, K., and Beraheng, S. (2008). "Reinforcement of maleated natural rubber by precipitated silica," Journal of Applied Polymer Science 109(6), 3839-3848. DOI: 10.1002/app.28483

Sengloyluan, K., Sahakaro, K., Dierkes, W. K., and Noordermeer, J. W. (2014). "Silicareinforced tire tread compounds compatibilized by using epoxidized natural rubber," European Polymer Journal 51, 69-79. DOI: 10.1016/j.eurpolymj.2013.12.010

Song, X., Ma, X., Li, Y., Ding, L., and Jiang, R. (2019). “Tea waste derived microporous active carbon with enhanced double-layer supercapacitor behaviors," Applied Surface Science 487, 189-197. DOI: 10.1016/j.apsusc.2019.04.277

Surya, I., Ismail, H., and Azura, A. (2013). "Alkanolamide as an accelerator, fillerdispersant and a plasticizer in silica-filled natural rubber compounds," Polymer Testing 32(8), 1313-1321. DOI: 10.1016/j.polymertesting.2013.07.015

Tian, L., Shen, B., Xu, H., Li, F., Wang, Y., and Singh, S. (2016). "Thermal behavior of waste tea pyrolysis by TG-FTIR analysis," Energy 103, 533-542. DOI: 10.1016/j.energy.2016.03.022

Uddin, M. T., Islam, M. A., Mahmud, S., and Rukanuzzaman, M. (2009). “Adsorptive removal of methylene blue by tea waste," Journal of Hazardous Materials 164(1), 53-60. DOI: 10.1016/j.jhazmat.2008.07.131

Utomo, H. D., and Hunter, K. (2006). "Adsorption of divalent copper, zinc, cadmium and lead ions from aqueous solution by waste tea and coffee adsorbents," Environmental Technology 27(1), 25-32. DOI: 10.1080/09593332708618619

Visakh, P., Thomas, S., Oksman, K., and Mathew, A. P. (2012). “Crosslinked natural rubber nanocomposites reinforced with cellulose whiskers isolated from bamboo waste: Processing and mechanical/thermal properties," Composites Part A: Applied Science and Manufacturing 43(4), 735-741. DOI: 10.1016/j.compositesa.2011.12.015

Article submitted: March 27, 2020; Peer review completed: May 16, 2020; Revised version received and accepted: December 19, 2020; Published: December 22, 2020.

DOI: 10.15376/biores.16.1.1230-1244 